Casas, L., Espinosa, A., Borràs-Santos, A., Jacobs, J., Krop, E., Heederik, D., Nemery, B., Pekkanen, J., Hyvärinen, A., Täubel, M., Zock, J.P. Domestic use of bleach and infections in children: a multicentre cross-sectional study. Occupational and Environmental Medicine:2015,7 72(8), 602-604

\begin{tabular}{|l|l|}
\hline $\begin{array}{l}\text { Postprint } \\
\text { Version }\end{array}$ & 1.0 \\
\hline Journal website & http://oem.bmj.com/content/72/8/602.long \\
\hline Pubmed link & http://www.ncbi.n/m.nih.gov/pubmed/?term=25838260 \\
\hline DOI & $10.1136 /$ oemed-2014-102701 \\
\hline
\end{tabular}

This is a NIVEL certified Post Print, more info at http://www.nivel.eu

\title{
Domestic use of bleach and infections in children: a multicentre cross-sectional study
}

\author{
LIDIA CASAS ${ }^{1,2,3,4}$, ANA ESPINOSA ${ }^{2,3,4,5}$, ALÍ́CIA BORRÀs-SANTOS ${ }^{2,3,4}$, JOSÉ JACOBS ${ }^{6}$, \\ ESMERAldA KROP ${ }^{6}$, Dick HEEDERIK ${ }^{6}$, BENOIT NEMERY ${ }^{1}$, JUHA PEKKANEN ${ }^{7,8}$, ANNE \\ HYVÄRINEN $^{7}$, MARTIN TÄUBEL ${ }^{7}$, JAN-PAUL ZOCK ${ }^{9,2,3}$ \\ ${ }^{1}$ Centre for Environment and Health, Department of Public Health and Primary Care, KU \\ Leuven, Leuven, Belgium \\ ${ }^{2}$ Centre for Research in Environmental Epidemiology (CREAL), Barcelona, Spain \\ ${ }^{3}$ CIBER Epidemiología y Salud Pública (CIBERESP), Barcelona, Spain \\ ${ }^{4}$ University Pompeu Fabra (UPF), Barcelona, Spain \\ ${ }^{5}$ Hospital del Mar Medical Research Institute (IMIM), Barcelona, Spain \\ ${ }^{6}$ Division of Environmental Epidemiology, Institute for Risk Assessment Sciences (IRAS), \\ Utrecht University, Utrecht, The Netherlands \\ ${ }^{7}$ Department of Health Protection, National Institute for Health and Welfare (THL), Kuopio, \\ Finland \\ ${ }^{8}$ Department of Public Health, University of Helsinki, Helsinki, Finland \\ ${ }^{9}$ Netherlands Institute for Health Services Research (NIVEL), Utrecht, The Netherlands
}

\begin{abstract}
Objective To report the effects of bleach use at home on the frequency of infections in 9102 school-age children participating in the HITEA project.

Methods Parents of pupils aged 6-12 years from schools in Barcelona province (Spain), Utrecht province (the Netherlands) and Eastern and Central Finland were administered a questionnaire including questions on the frequency of infections (influenza, tonsillitis, sinusitis, otitis, bronchitis and pneumonia) in the past 12 months and bleach use at home. We developed multivariable mixedeffects multilogistic regression models to obtain relative risk ratios (RRR) and their 95\% CI per country, and combined the RRR using random-effects metaanalyses.
\end{abstract}

Results Bleach use was common in Spain $(72 \%, n=1945)$ and uncommon in Finland $(7 \%, \mathrm{n}=279)$. Overall, the prevalence of infections (recurrent or once) was higher among children of bleach users. Significant combined associations were shown for influenza only once $(\mathrm{RRR}=1.20,95 \% \mathrm{CI} 1.04$ to 1.38$)$, recurrent tonsillitis (RRR $=1.35,95 \%$ CI 1.07 to 1.71$)$ and any infection (RRR=1.18, 95\% CI 1.01 to 1.38 ).

Conclusions Passive exposure to cleaning bleach in the home may have adverse effects on school-age children's health by increasing the risk of respiratory and other infections. The high frequency of use of disinfecting irritant cleaning 
Casas, L., Espinosa, A., Borràs-Santos, A., Jacobs, J., Krop, E., Heederik, D., Nemery, B., Pekkanen, J., Hyvärinen, A., Täubel, M., Zock, J.P. Domestic use of bleach and infections in children: a multicentre cross-sectional study. Occupational and Environmental Medicine:2015,7 72(8), 602-604

products may be of public health concern, also when exposure occurs during childhood.

\section{WHAT THIS PAPER ADDS?}

- Previous studies reported adverse respiratory health effects in children, associated with the exposure to cleaning products at home.

- Our cross-sectional multicentre study suggests that passive exposure to cleaning bleach in the home has an adverse effect on health in school-age children by increasing the frequency of respiratory and other infections.

- We observed geographical variation in the prevalence of bleach use and infections, and heterogeneity in the associations across countries.

- Further studies including more detailed descriptions of cleaning products use and objective measurements are needed to confirm our results.

\section{INTRODUCTION}

Results from birth cohort studies suggest that the use of cleaning agents may increase the risk of wheezing and respiratory infections during the first year of life, 1,2 and of persistent wheezing and airway inflammation at school-age.3-5 Furthermore, a cross-sectional study reported protective effects of living in a home where bleach was used on childhood asthma and allergic sensitisation, but increased risk of recurrent bronchitis at school-age. $6 \mathrm{We}$ report the effects of bleach use at home on the frequency of infections in 9102 school-age children participating in the HITEA project.7

\section{METHODS}

Pupils aged 6-12 years from 18 schools in Barcelona province (Spain), 19 schools in Utrecht province (the Netherlands) and 17 schools in Eastern and Central Finland were invited to participate. Written informed consent was obtained for all participants and the study was approved by local ethics committees. Selfadministered questionnaires on respiratory health and including an item on bleach use at home were sent to the parents. They reported the frequency (never, once, twice and $\geq 3$ times) of infections (influenza, tonsillitis, sinusitis, otitis, bronchitis and pneumonia) in the past 12 months. Bleach use was defined by a positive answer to the following question "Do you or anybody else use bleach to clean the child's home at least once a week?". In addition, information on weekly use of bleach for school cleaning was asked in a subset of the schools.

For statistical analyses, we recoded the frequency of each infection into three categories (never, once, recurrent $(>1)$ ) and created a combined 'any infection' variable (any report) with the three described categories. We developed multivariable mixed-effects multilogistic regression models to obtain relative risk ratios (RRR) and their $95 \%$ CI. Models were developed for each country and adjusted for sex, age, mould at home, passive smoking at home and parental education. School was included as random effect. In sensitivity analyses, bleach use for school cleaning was 
Casas, L., Espinosa, A., Borràs-Santos, A., Jacobs, J., Krop, E., Heederik, D., Nemery, B., Pekkanen, J., Hyvärinen, A., Täubel, M., Zock, J.P. Domestic use of bleach and infections in children: a multicentre cross-sectional study. Occupational and Environmental Medicine:2015,7 72(8), 602-604

considered as potential confounder in the subsample of children attending the schools that reported this information. Country-specific estimates were combined using random-effects meta-analysis. Data analysis was conducted with STATA SE V.12.0 statistical software (Stata Corporation, College Station, Texas, USA).

\section{RESULTS}

In total, 2690 children attending Spanish schools, 2490 attending Dutch schools and 3922 attending Finnish schools were included in the study. Table 1 shows a description of the population characteristics and prevalence of bleach use and infections. Bleach use was common in Spain (72\%) and uncommon in Finland (7\%). All Spanish schools were cleaned with bleach while the Finnish schools were not. Infections (once or recurrent) were generally most prevalent in Spain. Influenza infections were most prevalent in the Netherlands (11\% recurrent and $36 \%$ once). These differences across countries were statistically significant ( $\mathrm{p}$ value $<0.05$ ). Overall, the prevalence of infections (recurrent or once) was higher among children of bleach users. These differences were statistically significant (crude $p$ value $<0.05$ ) for influenza in the Netherlands, sinusitis and pneumonia in Finland, and any infection in Spain and Finland. Figure 1 shows the adjusted RRR per country and combined (cRRR). Generally, the prevalence of infections was higher in children exposed to bleach than in non-exposed in the three countries. The risk of one influenza episode in the previous year was higher among bleach users in the Netherlands (RRR $=1.27,95 \%$ CI 1.06 to 1.54 ). In Finland, significant associations were observed with recurrent tonsillitis ( $R R R=2.41,95 \%$ CI 1.25 to 4.66$)$ and sinusitis (RRR $=2.18,95 \%$ CI 1.19 to 4.00$)$, and in Spain with recurrent any infection ( $R R R=1.28,95 \%$ CI 1.00 to 1.63 ). In combined analyses, significant associations were shown for influenza only once (cRRR $=1.20,95 \%$ CI 1.04 to 1.38 ), recurrent tonsillitis (cRRR $=1.35,95 \%$ CI 1.07 to 1.71 ) and any infection (cRRR $=1.18,95 \% \mathrm{CI}$ 1.01 to 1.38). Regarding the risk of pneumonia (never vs ever), no significant effects were shown either per country (data not shown) or combined (cRRR $=1.06,95 \% \mathrm{CI}$ 0.72 to 1.56 ). The inclusion of bleach use at school in the models did not modify the estimates. However, bleach use for school cleaning in the Netherlands was independently associated with a higher risk of any recurrent infection $(\mathrm{RRR}=1.62$, $95 \%$ CI 1.01 to 2.62 ).

\section{[TABLE 1] [FIGURE 1]}

Adjusted associations (relative risk ratios (RRR) and 95\% CI) between infections and the household use of bleach at school-age, per country and combined. Adjusted for sex, age, mould at home, passive smoking at home and parental education. Random intercept: school.

\section{DISCUSSION}

Our results suggest that passive exposure to cleaning bleach at home is associated with an increased frequency of respiratory and related infections in school-age children. This is in line with the increased risk of recurrent bronchitis in school-age 
Casas, L., Espinosa, A., Borràs-Santos, A., Jacobs, J., Krop, E., Heederik, D., Nemery, B., Pekkanen, J., Hyvärinen, A., Täubel, M., Zock, J.P. Domestic use of bleach and infections in children: a multicentre cross-sectional study. Occupational and Environmental Medicine:2015,7 72(8), 602-604

children reported in a Belgian cross-sectional study.6 Consistently, studies in the British ALSPAC 3,4 and the French PARIS2 birth cohorts reported significant associations between the use of cleaning products and respiratory symptoms or infections, although these studies did not specifically evaluate the effects of bleach. Spanish studies focused on the effects of specific cleaning products on infections during infancy, 1 and lung function and airway inflammation at school-age. 5 Although they observed adverse effects for several products, they did not find significant associations with bleach. However, the widespread use of bleach in Spanish homes limited statistical power.

Domestic cleaning involves exposure to a large variety of irritants and sensitising chemicals that are used following certain cleaning patterns. Unfortunately, we did not have information on the use of other cleaning products and we cannot exclude the possibility that the observed results are due to the use of other irritants or to their combinations. Moreover, in Finland, where bleach use is very uncommon, its use may be determined by the presence of other indoor factors that could not be considered in our study (eg, dampness without mould). However, information on the use of bleach at school was available for a subsample of the study population (38\%) and reported 2 years after the administration of the health questionnaire. No differences in the effect estimates were observed when including this variable in the models. However, we observed increased risk of any recurrent infection among children attending schools cleaned with bleach in the Netherlands that is consistent with our findings regarding the effects of bleach use at home.

The frequency, amount and specific use of bleach helps determining the actual exposure. Moreover, geographical differences across countries in the frequency and specific use of bleach at home exist. 8 In our study, only basic information on the frequency of use was recorded and based on parental report. Therefore, children with very low exposure may have been classified in the same group as children with high exposure. This bias could differ across countries and may partly explain the differences observed across countries. Moreover, information on infections was also based on parental report and may have contributed to the reporting bias and country differences. Nevertheless, parental report through questionnaire has good repeatability for household characteristics and respiratory symptoms.9 Finally, with cross-sectional studies it is difficult to make causal inferences. Owing to the lack of objective measurements of exposure and health outcomes and the cross-sectional design of the study, caution needs to be exercised when interpreting our results.

Nevertheless, one major strength of our study is the inclusion of three geographically spread European regions that allowed the precise investigation of potential differences in the effects. Furthermore, we included a large number of children and collected information on the occurrence and frequency of six specific infections. Thus, we could investigate the effects on specific infections according to frequency instead of restricting the analyses to a combined infections variable only. In addition, the use of cleaning products is associated with respiratory symptoms and inflammation. 1,5 In our study, we did not find any statistically significant association between the use of bleach and asthma, rhinitis and cough (data not 
Casas, L., Espinosa, A., Borràs-Santos, A., Jacobs, J., Krop, E., Heederik, D., Nemery, B., Pekkanen, J., Hyvärinen, A., Täubel, M., Zock, J.P. Domestic use of bleach and infections in children: a multicentre cross-sectional study. Occupational and Environmental Medicine:2015,7 72(8), 602-604

shown). Therefore, it is very unlikely that these respiratory outcomes are confounding the associations between bleach and infections in our study.

Two potential mechanisms similar to those described for second-hand smoke and air pollution 10 may be hypothesised. The irritant properties of volatile or aerosolised compounds generated during the cleaning process damage the respiratory epithelium, causing inflammation8 and facilitating infections by local flora (eg, tonsillitis, sinusitis). The association with community-acquired infections such as influenza may be related to the potential immunosuppressive properties of bleach. 6,8

In line with the previous studies, our study suggests that passive exposure to cleaning bleach in the home may have adverse effects on school-age children's health.

However, the evidence is inconsistent across countries, the health effects are rather modest, and the exposure and health assessment and cross-sectional design are a limitation, not only in our study but also in the previous studies. Nevertheless, the high frequency of use of disinfecting cleaning products - caused by erroneous belief, reinforced by advertising, that our homes should be free of microbes - makes the modest effects reported in our study of public health concern. In addition, it calls for the performance of further studies in this field that include more detailed descriptions of bleach use and objective measurements of exposure and health outcomes that can confirm our results.

\section{Footnotes}

- Contributors LC drafted the work and was involved in the statistical analyses. AE performed the main statistical analyses. AB-S, JJ and EK were involved in the data collection and critically reviewed the manuscript. DH, BN, JP, AH and MT critically reviewed the manuscript. JPZ is the guarantor of this work. All authors contributed to the interpretation of the data and approved the version to be published.

- Competing interests None.

- Patient consent Obtained.

- Ethics approval Local ethics committees.

- Provenance and peer review Not commissioned; externally peer reviewed.

\section{REFERENCES}

1. Casas L, Zock JP, Carsin AE, et al. The use of household cleaning products during pregnancy and lower respiratory tract infections and wheezing during early life. Int $\mathrm{J}$ Public Health 2013;58:757-64. doi:10.1007/s00038-012-0417-2

2. Herr M, Just J, Nikasinovic L, et al. Influence of host and environmental factors on wheezing severity in infants: findings from the PARIS birth cohort. Clin Exp Allergy 2012;42:275-83. doi:10.1111/j.1365-2222.2011.03933.x

3. Sherriff A, Farrow A, Golding J, et al. Frequent use of chemical household products is associated with persistent wheezing in pre-school age children. Thorax 2005;60:45-9. doi:10.1136/thx.2004.021154

4. Henderson J, Sherriff A, Farrow A, et al. Household chemicals, persistent wheezing and lung function: effect modification by atopy? Eur Respir J 2008;31:547-54. 
Casas, L., Espinosa, A., Borràs-Santos, A., Jacobs, J., Krop, E., Heederik, D., Nemery, B., Pekkanen, J., Hyvärinen, A., Täubel, M., Zock, J.P. Domestic use of bleach and infections in children: a multicentre cross-sectional study. Occupational and Environmental Medicine:2015, 72(8), 602-604

5. Casas L, Zock JP, Torrent M, et al. Use of household cleaning products, exhaled nitric oxide and lung function in children. Eur Respir J 2013;42: 1415-18. doi:10.1183/09031936.00066313

6. Nickmilder M, Carbonnelle S, Bernard A. House cleaning with chlorine bleach and the risks of allergic and respiratory diseases in children. Pediatr allergy Immunol 2007;18:27-35. doi:10.1111/j.1399-3038.2006.00487.x

7. Borràs-Santos $\mathrm{A}$, Jacobs $\mathrm{JH}$, Täubel $\mathrm{M}$, et al. Dampness and mould in schools and respiratory symptoms in children: the HITEA study. Occup Environ Med 2013;70:681-7. doi:10.1136/oemed-2012-101286

8. Zock JP, Plana E, Antó JM, et al. Domestic use of hypochlorite bleach, atopic sensitization, and respiratory symptoms in adults. J Allergy Clin Immunol 2009;124:731-8.e1. doi:10.1016/j.jaci.2009.06.007

9. Strippoli MPF, Silverman M, Michel G, et al. A parent-completed respiratory questionnaire for 1-year-old children: repeatability. Arch Dis Child 2007;92:861-5. doi:10.1136/adc.2007.117978

10. Maclntyre EA, Gehring U, Mölter A, et al . Air pollution and respiratory infections during early childhood: an analysis of 10 European birth cohorts within the ESCAPE Project.

\section{TABLES AND FIGURES}

TABLE 1: DESCRIPTION (N AND \%) OF THE POPULATION CHARACTERISTICS, USE OF BLEACH AT HOME AT LEAST ONCE A WEEK AND RESPIRATORY INFECTIONS (N=9102)

\begin{tabular}{|c|c|c|c|}
\hline & Spain & The Netherlands & Finland \\
\hline & $n=2690$ & $n=2490$ & $n=3922$ \\
\hline Number of schools (n) & 18 & 19 & 17 \\
\hline Girls & $1304(48 \%)$ & $1295(52 \%)$ & $2036(52 \%)$ \\
\hline Age (mean, SD) & $9.0(1.8)$ & $9.1(1.8)$ & $10.0(1.8)$ \\
\hline Passive smoking & $751(28 \%)$ & $334(13 \%)$ & $0(0 \%)$ \\
\hline Mould at home & $168(6 \%)$ & $342(14 \%)$ & $93(2 \%)$ \\
\hline Low parental education & $1213(47 \%)$ & $967(41 \%)$ & $1913(50 \%)$ \\
\hline Bleach use at home & $1945(72 \%)$ & $1417(57 \%)$ & $279(7 \%)$ \\
\hline Bleach use at school* & $1108(100 \%)$ & $159(11 \%)$ & $0(0 \%)$ \\
\hline \multicolumn{4}{|l|}{ Infections } \\
\hline \multicolumn{4}{|l|}{ Influenza } \\
\hline Once & $363(18 \%)$ & $824(36 \%)$ & $598(17 \%)$ \\
\hline Recurrent & $142(7 \%)$ & $240(11 \%)$ & $224(6 \%)$ \\
\hline \multicolumn{4}{|l|}{ Tonsilitis } \\
\hline Once & $433(21 \%)$ & $274(13 \%)$ & $141(4 \%)$ \\
\hline Recurrent & $258(13 \%)$ & $114(5 \%)$ & $76(2 \%)$ \\
\hline \multicolumn{4}{|l|}{ Otitis } \\
\hline Once & $54(3 \%)$ & $78(4 \%)$ & $183(5 \%)$ \\
\hline
\end{tabular}


Casas, L., Espinosa, A., Borràs-Santos, A., Jacobs, J., Krop, E., Heederik, D., Nemery, B., Pekkanen, J., Hyvärinen, A., Täubel, M., Zock, J.P. Domestic use of bleach and infections in children: a multicentre cross-sectional study. Occupational and Environmental Medicine:2015,7 72(8), 602-604

\begin{tabular}{|c||l|l|l|}
\hline & Spain & The Netherlands & Finland \\
\hline \hline & $\mathbf{n = 2 6 9 0}$ & $\mathbf{n = 2 4 9 0}$ & $\mathbf{n = 3 9 2 2}$ \\
\hline \hline Recurrent & $48(3 \%)$ & $34(2 \%)$ & $95(3 \%)$ \\
\hline \hline Sinusitis & & & \\
\hline \hline Once & $331(17 \%)$ & $222(10 \%)$ & $460(13 \%)$ \\
\hline \hline Recurrent & $188(9 \%)$ & $153(7 \%)$ & $165(5 \%)$ \\
\hline \hline Bronchitis & & & \\
\hline Once & $160(8 \%)$ & $81(4 \%)$ & $238(7 \%)$ \\
\hline Recurrent & $145(7 \%)$ & $70(3 \%)$ & $45(1 \%)$ \\
\hline \hline Pneumonia $($ ever $)$ & $74(4 \%)$ & $45(2 \%)$ & $37(1 \%)$ \\
\hline \hline Any infection & & & $1068(29 \%)$ \\
\hline \hline Once & $815(35 \%)$ & $920(39 \%)$ & $504(14 \%)$ \\
\hline \hline Recurrent & $609(26 \%)$ & $495(21 \%)$ & \\
\hline \hline
\end{tabular}

${ }^{*} \mathrm{n}=3473$ (Spain $\mathrm{n}=1108$; the Netherlands $\mathrm{n}=1385$; Finland $\mathrm{n}=980$ ). 
Casas, L., Espinosa, A., Borràs-Santos, A., Jacobs, J., Krop, E., Heederik, D., Nemery, B., Pekkanen, J., Hyvärinen, A., Täubel, M., Zock, J.P. Domestic use of bleach and infections in children: a multicentre cross-sectional study. Occupational and Environmental Medicine:2015,7 72(8), 602-604

FIGURE 1: ADJUSTED ASSOCIATIONS (RELATIVE RISK RATIOS (RRR) AND 95\% CI) BETWEEN INFECTIONS AND THE HOUSEHOLD USE OF BLEACH AT SCHOOL-AGE, PER COUNTRY AND COMBINED.

Influenza

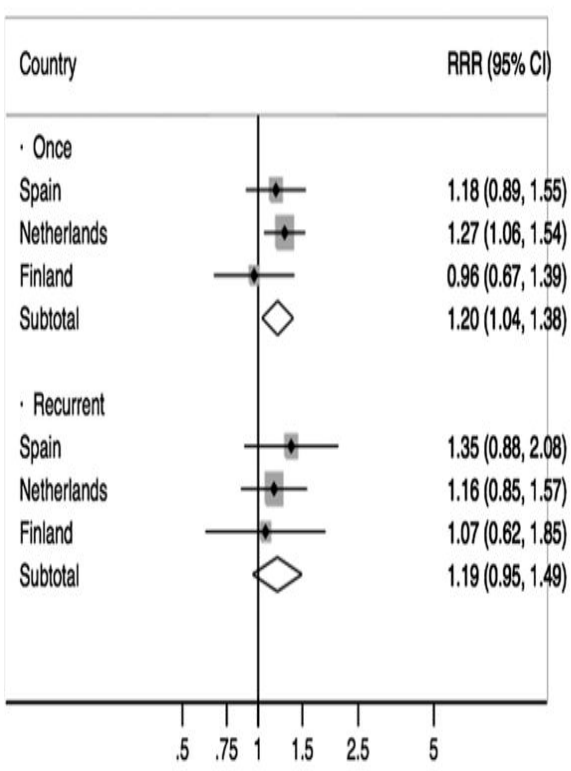

Otitis

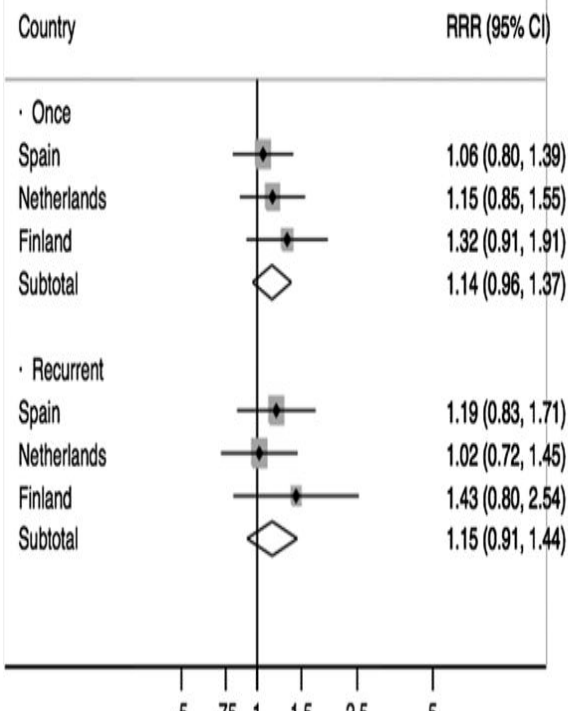

Tonsilitits

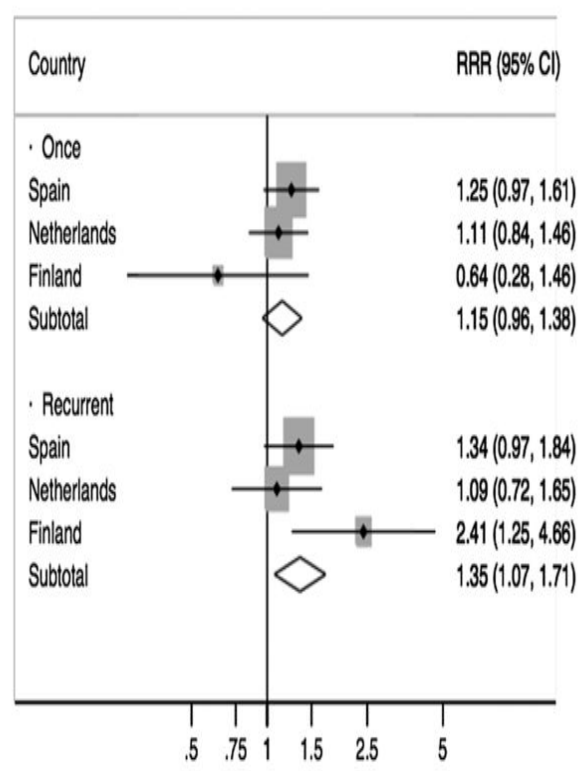

Bronchitis

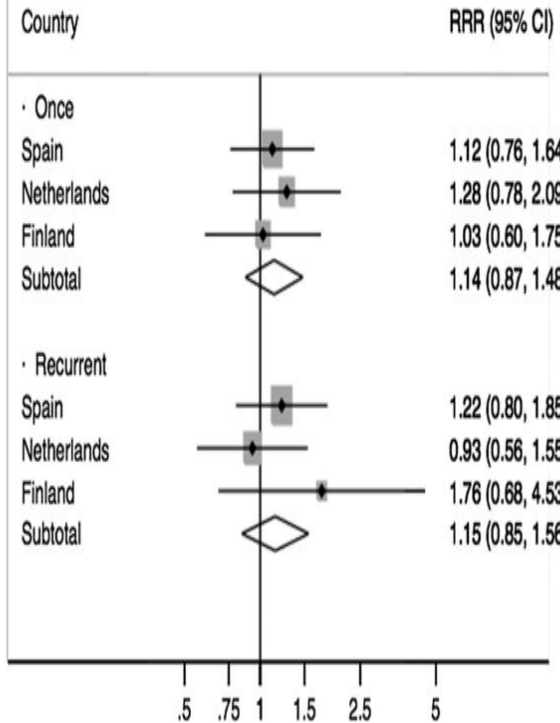

Sinusitis

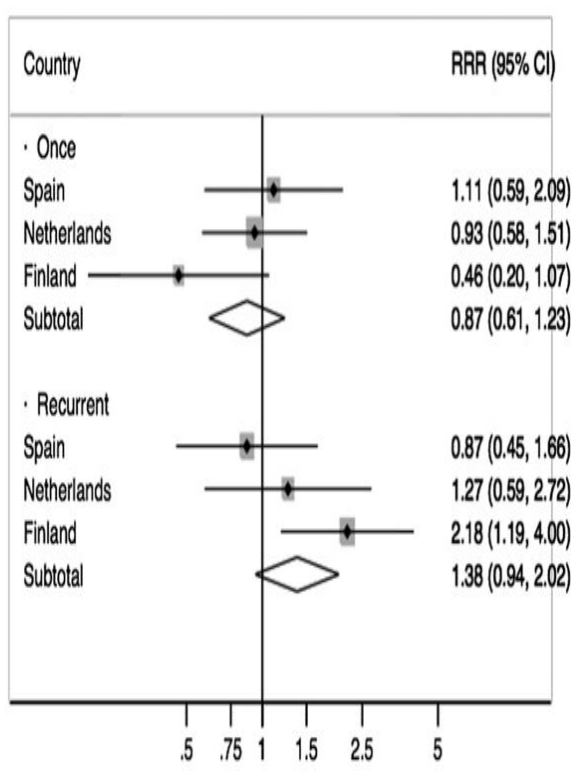

Any infection

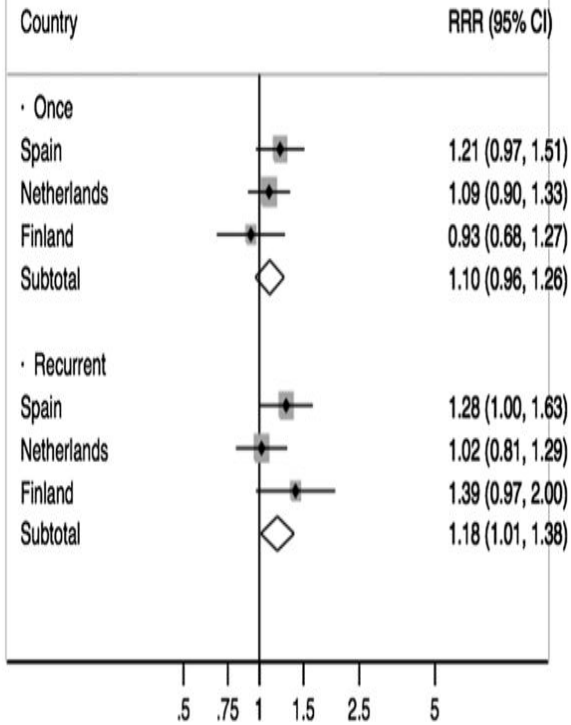

